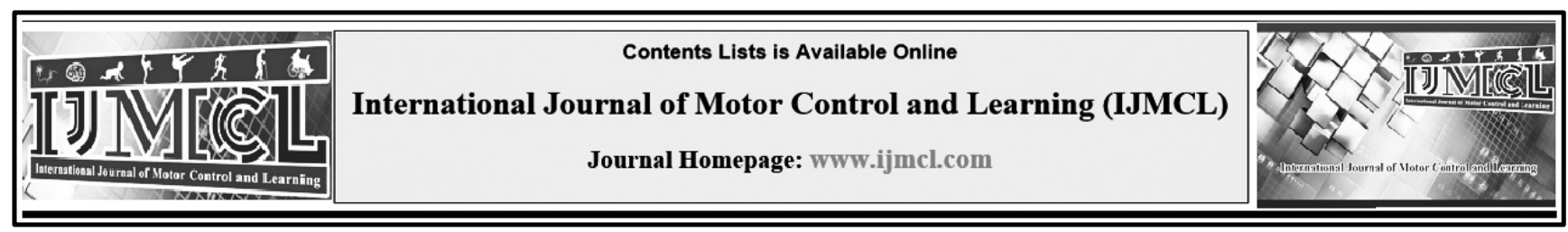

\title{
Prediction of Mental Well-being and General Health Based on Perceived Stress and Body Image with Mediating the Role of Self-compassion in Women Athletes in Tehran
}

\author{
Shadi Kabiri Aq Ziarat ${ }^{a}$, Afsaneh Taheri ${ }^{b^{*}}$, Khadijeh Abolmaali ${ }^{a}$ \\ ${ }^{\text {a }}$ Department of Health Psychology, Faculty of Psychology, Islamic Azad University Roudehen Branch (RIAU), Roudehen, Tehran, Iran \\ ${ }^{\mathrm{b}}$ Assistant Professor of Psychology, Faculty of Psychology, Islamic Azad University Roudehen Branch (RIAU), Roudehen, Tehran, Iran
}

\begin{tabular}{|c|c|}
\hline Keywords & Abstract \\
\hline Perceived Stress & Objective: This study aimed to predict mental well-being and general health based on \\
\hline Mental Well-being & $\begin{array}{l}\text { perceived stress and body image with mediating the role of self-compassion in women } \\
\text { athletes in Tehran. }\end{array}$ \\
\hline Body Image & Methods: This descriptive correlational study was performed using structural equations. \\
\hline Women Athletes & $\begin{array}{l}\text { The statistical population included all female athletes who referred to sports clubs in } \\
\text { Tehran. In this study, } 250 \text { women were selected by the convenience sampling method. }\end{array}$ \\
\hline General Health & Participants responded to questionnaire forms specified for measuring mental well-being, \\
\hline Self-compassion & $\begin{array}{l}\text { general health, self-compassion, body image, and perceived stress scale using a website } \\
\text { link. The obtained data were analyzed by descriptive analysis, Pearson correlation, and } \\
\text { path analysis using SPSS and PLS software statistical packages. }\end{array}$ \\
\hline $\begin{array}{l}\text { Afsaneh Taheri, } \\
\text { Email: } \underline{\text { a taher@yahoo.com }}\end{array}$ & $\begin{array}{l}\text { Results: In general, path analysis showed that self-compassion could not mediate the path } \\
\text { between perceived stress and mental well-being. However, it mediated the path of body } \\
\text { image to well-being. Besides, self-compassion did not mediate the perceived ester pathway } \\
\text { to public health and body image to public health. }\end{array}$ \\
\hline Received: 2021/02/16 & $\begin{array}{l}\text { Conclusion: According to the results, it is concluded that strategies reducing self- } \\
\text { compassion are able to provide a better body image and increase the mental well-being of } \\
\text { women athletes. }\end{array}$ \\
\hline Accepted: 2021/05/08 & \\
\hline
\end{tabular}

\section{Introduction}

Health is known as a human right, and a social goal in the world and is vital for satisfying the basic needs and improving the quality of human life. According to the World Health Organization Statute, public health is the complete physical, mental and social well-being of the individual, and a dynamic interaction exists between these three aspects. Therefore, according to this definition, health does include the physical aspect of individuals and the psychological and social facets (Namazi, Alizadeh, \& Kouchakzadeh-Talami,
2015). A high score of physical health in the general health questionnaire does not indicate physical disorder, but it denotes that an individual is more prone to develop a physical illness (Ansari, Bahrami, Akbarzade, \& Bakhasanim, 2007). Mental well-being is one of the most significant components of health. Mental well-being is a field of positive psychology and a component of an individual concept dealing with cognitive and emotional evaluation of individuals from different areas and aspects of their lives. Mental well-being includes interrelated cognitive and emotional 
components. The cognitive dimension deal with the cognitive assessment of mental health and quality of life, while the emotional dimension deals with having maximum positive emotion and minimum negative emotion (Steptoe, Deaton, \& Stone, 2015). Since mental well-being is one of the most significant indices of mental health, quality of life, and life satisfaction, and numerous factors, such as social, personality, emotional, cultural, occupational, play a role in the well-being of individuals, so it is necessary to assess the mental health care factors related to mental well-being (Friedman \& Kern, 2014). There is growing evidence that self-compassion is an important source of happiness and psychological well-being (Wollast et al., 2019). Neff (2003) indicated that self-compassion is composed of three main components, namely kindness to oneself in the face of self-judgment, common human feeling in the face of isolation, and mindfulness in the face of extreme imitation. These components combine to interact with the mind to create a pattern of selfcompassion (Neff, 2003; Neff, 2016). Selfkindness requires calmness, support, and selfconsciousness. Instead of attacking and silencing oneself against one's own shortcomings, one offers warm, unconditional acceptance (even if certain behaviors may be identified as useless and in need of change) instead of treating oneself with harsh criticism or judgment (Neff \& Sands, 2015). It also includes soothing and actively relaxing oneself in times of distress. Human commonalities are comprised of recognizing the common human experience, understanding that all human beings fail and make mistakes that all result in imperfect lives. It enables oneself to develop a broader and more connected perspective on personal flaws and personal problems instead of feeling isolated in his or her personal flaws (Neff, 2011). Mindfulness is the third component of self-compassion, being aware of the momentary experiences of one's presence and suffering from clarity and balance, not ignoring and eliminating one's negative dimensions or life experience (Raab, 2014). Selfcompassion can be directed toward oneself when suffering occurs through one's own shortcomings when life's external conditions are simply painful or difficult to bear. However, self-compassion is associated with when suffering is due to one's recklessness in individual actions or failures (Zessin, Dickhäuser, \& Garbade, 2015). Studies have shown a high prevalence of body image dissatisfaction among young people throughout life. Young people form their personal and social identities as well as a number of changes that coincide with biological maturity, which leads to increased concern about the body and appearance (Tiggemann, 2012). People who do not have a socially justified physical appearance are overly involved with physical appearance and exhibit body image dissatisfaction, while sexual intercourse is a key factor in the determination of body image dissatisfaction. This is because the body has been experienced and observed from at least two different perspectives (Vartanian, 2012). The first view refers to the numerous alterations that occur in the cognitive, emotional, and social spheres, while the second view pertains to the socially acceptable beauties available by the media. This process directly impacts self-concept, which 
can be defined as how one describes oneself, the definition of one's idea of oneself, and one's desires in relation to what one wants (Lemes, Câmara, Alves, \& Aerts, 2018). Previous research has shown a significant correlation between body image attitudes and mental health/well-being, especially in adult women (Walker, White, \& Srinivasan, 2018). Compared with men, appearance and body satisfaction are strongly associated with women's self-esteem and identity. Studies indicate that women's individual selfassessment of the physical self is closely related to global self-assessment, such as self-concept and life satisfaction, and specific dimensions of wellbeing, such as self-esteem and self-worth (Badenes-Ribera, Fabris, \& Longobardi, 2018; Dahlenburg, Gleaves, Hutchinson, \& Coro, 2020; Morrison, Morrison, \& Sager, 2004). Negative body image, such as body dissatisfaction, is associated with a range of unhealthy mental health consequences, such as the increased likelihood of eating and mood disorders, mental distress such as increased symptoms of depression and anxiety, low self-esteem, and poor mental adjustment, among young and middle-aged women (Gow et al., 2020). In addition, it should be noted that in recent years, the ideality of the body has been increasingly defined as excessive weight loss, and many adolescents, especially girls, find weight loss particularly attractive. Negative emotions, behaviors, and inappropriate cognitive processes about an individual's body image lead to distortion of the physical image and negative self-concept that may be the result of overweight and obesity (Kantanista, Osiński, Borowiec, Tomczak, \& Król-
Zielińska, 2015). Another factor related to mental well-being is perceived stress (Otter, Brink, van der Does, \& Lemmink, 2016). Life events do not affect people in the same way; rather, the way of interpretation of events affects their mental health (Ebstrup, Eplov, Pisinger, \& Jørgensen, 2011). Stress influences their mental well-being through coping styles (Hampel \& Petermann, 2006). In this regard, Sheivandi, Naeimi, \& Farshad (2016) presented a structural model of self-compassion and psychological well-being mediated by selfesteem and body image in female students. They found that self-compassion predicts body image and self-esteem, body image predicts psychological well-being, and self-esteem predicts body image. Pop (2017) also showed that physical activity, body image, and mental well-being showed that physical activity has a positive effect on mental health and enhances emotional state as well as the incidence and severity of diseases and traumatic conditions, such as cardiovascular diseases, type 2 diabetes, osteoarthritis, osteoporosis, and obesity. This study was designed considering the small number of studies in Iranian women athletes and the extent to which compassion can automatically modulate stress and body image and affect mental well-being and health. Therefore, the main purpose of this study was to predict mental well-being and general health based on perceived stress and body image with mediating the role of self-compassion in women athletes in Tehran. 


\section{Method}

\section{Participants}

The statistical population of the present study consisted of all female athletes who referred to sports clubs in Tehran. Of these, 250 people voluntarily participated in this study after meeting the inclusion criteria. Due to the lack of information about the precise and actual volume of the population, the sample size was selected according to the type of research goal (Kline,
2011). In this study, participants could withdraw from the study at any time without justification. We also provided scores and status reports for anyone who wanted. The survey was anonymously performed, and the confidentiality of the data was in accordance with the Privacy Policy and the Helsinki Declaration (Association, 2013). Table 1 reports the demographic indicators of this study.

Table 1. Demographic characteristics of participants.

\begin{tabular}{|l|l|l|l|}
\hline Variable & & n (average) & $\%$ (SD) \\
\hline \multirow{4}{*}{ Marital status } & single & 166 & 66.4 \\
\cline { 2 - 4 } & Married & 66 & 26.4 \\
\cline { 2 - 4 } & Separated/ Widow & 18 & 2.7 \\
\hline \multirow{4}{*}{ Education } & Undergraduate & 66 & 26.4 \\
\cline { 2 - 4 } & Bachelor & 115 & 46 \\
\cline { 2 - 4 } & \multirow{2}{*}{ Master } & 51 & 20.4 \\
\hline \multirow{2}{*}{ Age } & PhD & 18 & 7.2 \\
\hline Family members & near & 22.31 & 9.54 \\
\hline
\end{tabular}

\section{Psychological Measurements}

\section{Mental Well-Being Questionnaire}

This questionnaire was prepared by Keyes \& Magyar-Moe, (2003). In this questionnaire, mental well-being refers to the scores obtained from the positive emotion scale, the absence of negative emotion, and overall life satisfaction. The component of total life satisfaction is evaluated by a one-question scale, and the components of positive and negative emotion are evaluated using six positive and negative expressions, respectively. In this questionnaire, participants must rate their overall life satisfaction on a 10 -point scale from 0 (worst possible conditions) to 10 (best possible conditions). This questionnaire is scored on a 5point Likert scale from no time (1) to full time (5).
Negative emotion scale items are inversely scored. Therefore, higher positive scores on this scale denote less negative emotional experience, and in items belonging to the positive emotion scale, higher scores imply more positive emotional experience. Scores are added together to create any scale. In a study conducted by Barghi Irani, Bakhti, \& Bagiyan Agiyankulemare (2015), the validity and reliability of the Persian version of this questionnaire were confirmed.

\section{General Health Questionnaire}

This questionnaire was developed by Goldberg \& Hillier (1979). The questionnaire includes 60 questions and assesses factors related to anxiety/sleep disorder, physical condition, social 
functioning, depression, and general health. The sum of the scores of the mentioned factors demonstrates the general score of general health. Tabatabaei \& Rasouli (2018) evaluated the reliability of the general health questionnaire based on three methods of retesting, halving, and Cronbach's alpha, which obtained reliability coefficients of $0.93,0.70$, and 0.90 , respectively. Also, in this survey, simultaneous methods and factor analysis were used to evaluate the validity of the mental health questionnaire, which has shown appropriate fit indices.

\section{Self-compassion Questionnaire}

The self-compassion questionnaire was developed by Neff, (2003), which includes 26 items and 6 components of self-kindness, selfjudgment, human commonalities, isolation, extreme awareness or mindfulness, and imitation in a 5-point Likert scale from strongly disagree $=1$ to strongly agree $=5$ scores. Items $1,2,4,6,8,11,13$, $16,18,20,21,24$ and 25 have inverse scoring. In a study carried out by Azizi, Mohammadkhani, Foroughi, \& Bahramkhani (2013), the validity and reliability of the Persian version of this questionnaire were confirmed.

\section{Body Image Questionnaire}

This questionnaire contains 68 questions answered by individuals and is designed to assess the individual's attitudes about various dimensions of the body image structure (Brown, Cash, \& Mikulka, 1990). This questionnaire consists of three scales: a) The scale related to the body itself; all questions except the number of questions presented in the following two subscales, which are scored as follows: 1 for "strongly disagree," 2 for "somewhat disagree," 3 for "I have no opinion," 4 for "somewhat agree" and a score of 5 for "strongly agree," B) Satisfaction scale is calculated for different body parts of questions 60 to 68 , with a score of 1 for "completely dissatisfied," 2 for "somewhat dissatisfied," 3 for "no opinion," 4 for "somewhat satisfied" and 5 for "completely satisfied," C) The scale of an individual's attitude towards weight, which includes questions 20, 56, 57, 58, 59 and 66. This scale includes two parts: mental engagement and assessment of one's weight. The validity of the main sections of the questionnaire was reviewed and confirmed by Brown et al. In 1990, and its reliability was reported to be 0.81 . The validity and reliability of this questionnaire have been confirmed in the Iranian population (Zarshenas et al., 2010).

\section{Perceived stress scale}

The extended version of the perceived stress scale was developed in 1983 by Cohen, Kamarck, \& Mermelstein (1994), which includes a 14-point Likert scale and is ranked from 0 to $4(0=$ Never, $1=$ very little, $2=$ sometime, $3=$ high, $4=$ very high). The lowest score is zero, and the highest is 56. A higher score indicates higher perceived stress. The perceived stress scale measures two subscales: a) The negative perception subscale, including items $1,2,3,4,11,12$, and 14, (B) positively perceived stress subscale comprising items 5, 6, 7, 8, 9, 10, and 13, scored in reverse. The validity and reliability of this questionnaire have been confirmed in the Iranian population 
(Maroufizadeh, Zareiyan, \& Sigari, 2014).

\section{Procedures}

All participants completed the questionnaire via a website link. Website links were distributed through a range of methods, such as invitations via email and social media platforms. The survey included an introductory page outlining the objectives of the survey and ethical information for participants. In order to collect demographic and epidemiological variables, a special questionnaire and self-report were prepared. Participants also answered other questionnaires. In order to ensure the quality of the survey, the response amplitude of some items was adjusted (some items required a reverse response), and participants were encouraged to respond carefully through the questionnaire description. In addition, questionnaires completed in less than 1 minute or more than 20 minutes were excluded from the analysis.

\section{Statistical analysis}

Descriptive statistical methods, including center orientation and dispersion indices, were applied. Also, the normality of the data distribution was measured using the Kolmogorov-Smirnov test, and the results showed that the obtained data were not normally distributed. The L-N conversion method was utilized to convert the data into normal conditions. Then, the Pearson correlation coefficient was employed to examine the relationship between variables. Path analysis was also used to assess the mediating role of variables and direct and indirect paths, performed with PLS software (Tabachnick, Fidell, \& Ullman, 2007). Other analyses were conducted by the SPSS software version 22 , and the significance level was considered 0.05 .

\section{Results}

The results of descriptive statistics of variables as well as correlation matrix between variables are reported in Table 2.

Table 2. Descriptive statistics of variables and Pearson correlation coefficients.

\begin{tabular}{|c|c|c|c|c|c|}
\hline Variable & 1. Perceived stress & 2.Mental well-being & 3.Body image & 4. General health & 5. Self-compassion \\
\hline 1 & - & $-0.433^{* *}$ & $-0.612 * *$ & $-0.432 * *$ & $0.237 * *$ \\
\hline 2 & & - & $0.340 * *$ & 0.178* & $-0.398 * *$ \\
\hline 3 & & & - & 0.136* & $-0.266^{* *}$ \\
\hline 4 & & & & - & -0.080 \\
\hline 5 & & & & & - \\
\hline Average & & & & & \\
\hline Standard deviation & & & & & \\
\hline
\end{tabular}

Note: $* \mathrm{p}<0.05, * * \mathrm{p}<0.01$

As depicted in Table 2, there is a positive and significant relationship between perceived stress with self-compassion, general health with mental well-being, as well as general health and mental well-being with body image $(\mathrm{p}<0.05)$. On the other hand, there was a negative and significant correlation between perceived stress with mental well-being as well as general health and body 
image. There was also such a relationship between body image with self-compassion and mental wellbeing with self-compassion $(p<0.05)$. It should be noted that the association between general health and compassion was not statistically significant $(\mathrm{p}$ $>0.05)$.

In order to evaluate the external model, the combined reliability, Cronbach's alpha, and convergence validity (means of extracted variance) were analyzed (Fornell \& Larcker, 1981). As displayed in Table 3, all variables have a combined variance above 0.4 with combined reliability of 0.7 and Cronbach's alpha above 0.6. The convergent reliability and validity of the present study can be confirmed.

Table 3. Convergence validity and combined reliability.

\begin{tabular}{|c|c|c|c|c|c|c|c|c|}
\hline Variable & $\begin{array}{c}\text { Average of } \\
\text { variance } \\
\text { extracted } \\
\text { (AVE) }\end{array}$ & $\begin{array}{l}\text { Combined } \\
\text { reliability }\end{array}$ & $\begin{array}{c}\text { Cronbach's } \\
\text { alpha }\end{array}$ & $\begin{array}{c}\text { Perceived } \\
\text { stress }\end{array}$ & $\begin{array}{c}\text { Mental } \\
\text { well- } \\
\text { being }\end{array}$ & $\begin{array}{c}\text { Body } \\
\text { image }\end{array}$ & $\begin{array}{c}\text { General } \\
\text { health }\end{array}$ & $\begin{array}{c}\text { Self- } \\
\text { compassion }\end{array}$ \\
\hline $\begin{array}{l}\text { Perceived } \\
\text { stress }\end{array}$ & 0.896 & 0.945 & 0.884 & 0.946 & & & & \\
\hline $\begin{array}{l}\text { Mental well- } \\
\text { being }\end{array}$ & 0.850 & 0.944 & 0.912 & $\begin{array}{r}- \\
0.440\end{array}$ & 0.922 & & & \\
\hline Body image & 0.766 & 0.907 & 0.849 & 0.590 & 0.316 & 0.875 & & \\
\hline $\begin{array}{c}\text { General } \\
\text { health }\end{array}$ & 0.400 & 0.758 & 0.600 & 0.457 & 0.171 & 0.118 & 0.624 & \\
\hline $\begin{array}{c}\text { Self- } \\
\text { compassion }\end{array}$ & 0.755 & 0.946 & 0.923 & 0.230 & 0.413 & 0.276 & $\begin{array}{r}- \\
0.061\end{array}$ & 0.869 \\
\hline
\end{tabular}

In the differential validity part, the difference between the indices of one construct and the indices of another construct in the model was compared. This could be calculated by the comparison of the AVE root of each construct with the values of correlation coefficients between the constructs. If the constructs are more correlated with their respective indices than with other constructs, the appropriate divergence or differential validity of the model is confirmed. To this aim, a matrix must be formed, which is the values of the main diagonal of the square root matrix of each construct. The low values of the main diagonal are the correlation coefficients between the construct and other constructs. In addition, in order to evaluate divergent validity, one of the newest evaluation criteria in this section, using the variance-based approach, is to use a criterion of different traits to the same traits ratio. Based on the matrix of methods and traits and according to the study of Henseler, Ringle, \& Sarstedt (2015), based on the optimal cut-off point less than 0.85 or 0.90 for each trait in each construct, so in the section related to the evaluation of divergent validity, appropriate variables are estimated. 


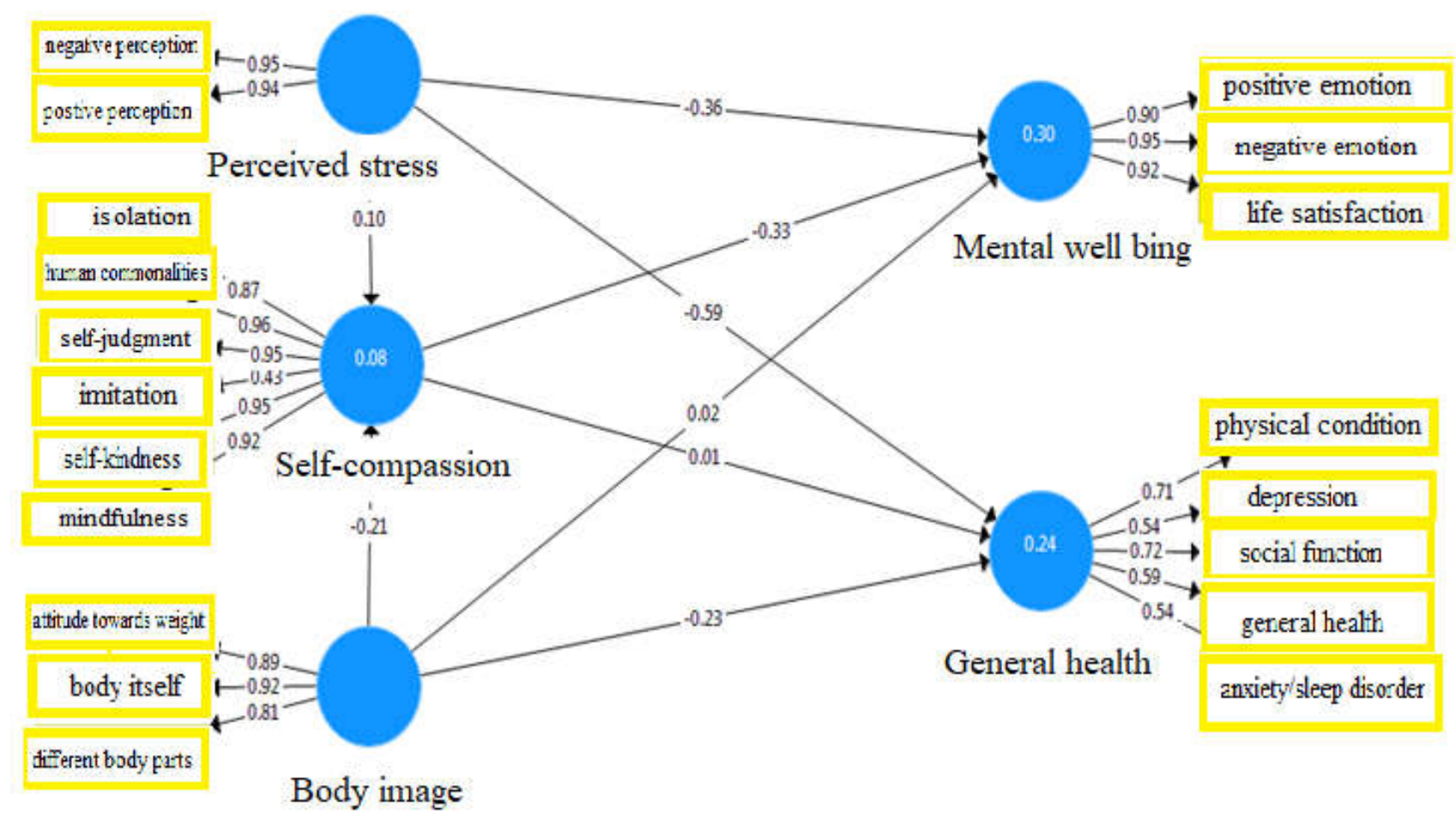

Figure 1. The analysis of the path model.

Figure 1 shows the path model analysis. Also, in Table 4, the fitting indices, effect size, coefficient of determination, and predictive power are reported. The coefficient of determination is a criterion used to connect the measurement part and the structural part of structural equation modeling and exhibits the impact of exogenous variables on endogenous variables. In this regard, and in accordance with the results obtained, the construct of self-compassion is $0.08 \%$ perceived by stress, and the body image is explained; also, the constructs of mental well-being and general health are explained by 0.30 and 0.24 by the whole model, respectively.

Table 4. The model fit indices, Cohen effect size, and determination coefficient.

\begin{tabular}{|c|c|c|c|c|c|c|c|c|c|}
\hline \multirow[b]{2}{*}{ Variable } & \multicolumn{3}{|c|}{ Determinant and predictive power } & \multirow[b]{2}{*}{ Variable } & \multicolumn{3}{|c|}{ Cohen effect size } & \multirow{2}{*}{$\begin{array}{l}\text { Index } \\
\text { SRMR }\end{array}$} & \multirow{2}{*}{$\begin{array}{l}\text { value } \\
0.078\end{array}$} \\
\hline & $\begin{array}{l}\text { Coefficient of } \\
\text { determination }\end{array}$ & $\begin{array}{c}\text { Modified } \\
\text { coefficient } \\
\text { of } \\
\text { prediction }\end{array}$ & Prediction & & $\begin{array}{c}\text { Self- } \\
\text { compassion }\end{array}$ & $\begin{array}{c}\text { General } \\
\text { health }\end{array}$ & $\begin{array}{c}\text { Mental } \\
\text { well- } \\
\text { being }\end{array}$ & & \\
\hline $\begin{array}{c}\text { Mental } \\
\text { well-being }\end{array}$ & 0.297 & 0.288 & 0.231 & $\begin{array}{c}\text { Perceived } \\
\text { stress }\end{array}$ & 0.008 & 0.303 & 0.116 & d_ULS & 1.163 \\
\hline $\begin{array}{l}\text { General } \\
\text { health }\end{array}$ & 0.244 & 0.235 & 0.078 & Body image & 0.033 & 0.044 & 0.001 & d_G & 0.852 \\
\hline $\begin{array}{c}\text { Self- } \\
\text { compassion }\end{array}$ & 0.083 & 0.076 & 0.056 & $\begin{array}{c}\text { Self- } \\
\text { compassion }\end{array}$ & 0.139 & 0.001 & & $\begin{array}{c}\text { Chi- } \\
\text { Square }\end{array}$ & 845.218 \\
\hline & & & & & & & & NFI & 0.771 \\
\hline
\end{tabular}


For each path, the effect size could be estimated using Cohen $\mathrm{F}^{2}$ (Table 4). According to Cohen's effect size, the values of $0.02,0.15$, and 0.35 for $\mathrm{F}^{2}$ represent the effect size of small, medium, and large, respectively. As indicated in Table 4, all paths are positive and have a small effect size, except for the perceived stress path and general health, which have a moderate effect size. Finally, the last criterion to be examined is the SRMR index. The SRMR index is between 0 and 1; the closer it is to zero, the more appropriate it is. A value of less than 0.1 for the SRMR index as a suitable criterion for partial least squares can indicate the desirability of the model. As shown in Table 4, the SRMR index indicates the desirability of the model in partial least squares. For other indicators in the fitting model, the researchers have not yet reached a general agreement on their threshold in PLS version 3 software. Therefore, the SRMR index is sufficient for the fitting model (Hair Jr, Hult, Ringle, \& Sarstedt, 2016). Finally, the results of each of the model paths in direct and indirect mode are reported in Table 5.

Table 5. The results of the path model in the study of mental well-being and general health based on perceived stress and body image mediated by self-compassion.

\begin{tabular}{|c|c|c|c|c|c|}
\hline Direct path & value & SD & $\mathbf{t}$ & sig & result \\
\hline Perceived stress-> Mental well-being & -0.365 & 0.085 & 4.147 & 0.001 & Confirm \\
\hline Perceived stress- $>$ General health & -0.959 & 0.074 & 8.045 & 0.001 & Confirm \\
\hline Perceived stress ->Self-compassion & 0.103 & $\mathbf{0 . 0 7 3}$ & 1.395 & 0.164 & Reject \\
\hline Body image-> Mental well-being & -0.016 & 0.082 & 0.197 & 0.844 & Reject \\
\hline Body imaging-> General Health & -0.229 & 0.078 & 2.298 & 0.004 & Confirm \\
\hline Body image-> Self-compassion & -0.215 & 0.083 & 2.599 & 0.010 & Confirm \\
\hline Self-compassion -> Mental well-being & -0.326 & 0.065 & 5.041 & 0.001 & Confirm \\
\hline Self - Compassion ->General Health & 0.013 & 0.055 & 0.231 & 0.817 & Reject \\
\hline \multicolumn{6}{|l|}{ Indirect path } \\
\hline Perceived stress ->Self-compassion -> Mental well-being & -0.034 & 0.026 & 1.331 & 0.190 & Reject \\
\hline Body image $->$ self-compassion $->$ Mental well-being & $\mathbf{0 . 0 7 0}$ & $\mathbf{0 . 0 3 3}$ & 2.119 & $\mathbf{0 . 0 3 5}$ & Confirm \\
\hline Perceived stress-> Self-compassion $->$ General health & 0.011 & 0.007 & 0.177 & 0.860 & Reject \\
\hline body image- $>$ Self-compassion- $>$ General health & 0.003 & 0.012 & 0.227 & 0.824 & Reject \\
\hline
\end{tabular}

According to the results of Table 5, in paths of perceived stress to self-compassion, body image, mental well-being, self-compassion, and general health were rejected, whereas other paths of the model were confirmed. The results of indirect paths of the model also demonstrate that the path of perceived stress to well-being with the mediating role of self-compassion is not statistically significant ( $p>0.05)$. However, the path of body image to mental well-being with the mediating role of self-compassion was statistically significant ( $\mathrm{p}=$ 0.035). In addition, the two paths of perceived 
stress and body image to general health with the mediating role of self-compassion were not statistically significant $(\mathrm{p}>0.05)$.

\section{Discussion and Conclusion}

In the present study, it was shown that perceived stress is negatively associated with mental well-being in women athletes in Tehran. This finding is consistent with previous studies (Cooper, 2013; Griffin \& Clarke, 2011; Kaveh, Alizadeh, Delavar, \& Borjali, 2011; Lai \& Plakiotis, 2020; Shakori, Khosrojavid, \& Salehi, 2015). It seems that stress is the stimulus of any situation that has unusual requests and requires a change in the current lifestyle. Stress is a situation in which one's environmental exchanges lead to real or unrealistic discrepancies between one's environmental will and biological and psychological resources or one's social systems (DuPont et al., 2020). Psychological well-being is the emotional and cognitive reactions to understanding the abilities and personal characteristics of effective interaction with the world in a proper relationship with society and positive growth and development over time, including life satisfaction, as well as energy and positive mood. According to the research findings, it can be argued that stress is inversely related to mental well-being, and as stress is decreased, life satisfaction, interaction with the world and energy, and positive mood is increased (Seligman, Rashid, \& Parks, 2006). Our results showed a negative and significant relationship between perceived stress and general health. These findings are consistent with previous studies (Garfin, Thompson, \&
Holman, 2018). In view of this finding, it can be said that stress (psychological stress), as one of the most important causes of diseases in humans, has attracted the attention of psychotherapists and physicians. New societies today impose more stress on human beings than has existed throughout human history. In fact, this stress remains throughout childhood, years of education, and adulthood in humans. Almost in all occupations and professions, everyone suffers from some kind of stress. Even within the family, the relationship between a man and a woman, which is considered to be the most fundamental relationship among all types of human relationships, is affected by conflicts and consequently psychological pressures. Stress is an integral part of everyday life for all human beings. Although small, temporary, and non-permanent amounts of stress can motivate and improve (Tissera, Auger, Séguin, Kramer, \& Lydon, 2020), creating and stabilizing the permanent and long-term stress in a person can cause two-sided problems that on the one hand, stress has a negative effect on the family, work, and society, and on the other hand, has a biological impact on the individual and causes psychosomatic complications, such as asthma attacks, indigestion, psychotic nausea, vomiting, sleep disorders, as well as gastric and duodenal ulcers. The current world around civilized human beings is inundated with stressors that cause a person to suffer from various mental and physical disorders. Progress is itself the designer and creator of new problems. Stress is not inherently a negative phenomenon, as moderate stress is part of an individual's health and is a motivating factor for adapting to new 
situations. However, if stress is not controlled or managed, it can have adverse effects on the physical health of individuals (Gnam et al., 2019). The analysis of the model revealed that the association between perceived stress and selfcompassion is not statistically significant. This finding is not in line with previous studies (Homan \& Sirois, 2017; Perez-Blasco, Sales, Meléndez, \& Mayordomo, 2016). It appears that according to Neff's theory, athletes with high self-compassion show a better response to stressors due to less focus on the negative aspects of their diseases (Neff, 2003). This makes them less perceived stress and better able to cope with their physical and mental problems, thus improving their life satisfaction and ultimately reducing their perceived stress. The point is, self-compassion can help people to stay healthy more effectively; since with this approach, they learn to be kind to themselves, to feel common with others, to be aware of their living conditions, and to face issues and problems with a nonjudgmental attitude. In other words, athletes with higher self-esteem judge themselves less harshly, accept their physical and mental illnesses more easily, and their self-assessments and reactions are based on their actual performance (Neff \& Sands, 2015). Due to the high acceptance of athletes, these people are less prone to anxiety, depression, and stress. In addition, the findings show that there is a significant relationship between body image and general health, which means that the better the body image of women athletes, the better their sense of health. This finding is also consistent with the results previous studies (Adams \& Leary, 2007; Cash, 2004). Dissatisfaction with one's body image endangers his/her mental health and makes him/her depressed. It seems that one of the most significant aspects of people's health is their physical and visual appearance. Cultural and social values and society's emphasis on apparent attractiveness, comparing people in appearance and value to beautiful people and facilitating things for them, and on the other hand, creating a feeling of inferiority due to bad appearance or the experience of ridicule by others, sensitizes individuals to their body image, lowers their self-confidence, reduces social relationships, and ultimately leads to lower social feelings and rejection in individuals. Thus, the worsening of such psychological considerations increases the likelihood of developing mental and physical disorders. It should be noted that exercise is an essential factor in improving body image and consequently increasing a person's health. Therefore, these two categories can affect each other bilaterally.

Another line of research showed that the relationship between body image and selfcompassion is not significant. This finding is in contrast to findings of previous studies (Dijkstra \& Barelds, 2011; Wood-Barcalow, Tylka, \& Augustus-Horvath, 2010). One aspect of selfcompassion is less self-judgment, which is probably not the case for women athletes in this study. Regardless of body size, face shape, or being different from social ideals, women seem to be more compassionate about their physical appearance, which is probably not the case with female athletes. The self-compassionate person does not avoid painful feelings but approaches them with kindness, understanding, and a sense of 
human commonality (Braun, Park, \& Gorin, 2016). It should be noted that the population in previous studies is different from the present study. Also, the tools used are different from previous studies. Also, age is an important factor in these studies that should be considered. Another direct path of the model showed that there is no direct relationship between body image and mental well-being in women athletes. Disorders in body image can result in causing some problems, such as anorexia, mental disorders, weight change, sleep disorders, lack of energy, anxiety, depression, self-blame, and guilt for no reason, and eating disorders. Research has shown that body image is associated with depression, social phobia, and anxiety (Cash, 2004). Women with a good body image are less likely to make social comparisons that lead to anxiety and depression; therefore, the psychological well-being of women who have a favorable body image is higher than those who have an undesirable body image (Sheivandi et al., 2016). In this regard, it should be noted that women athletes are likely to have desirable levels of wellbeing and body image, so this relationship is not statistically significant, although most studies in this field have been performed on non-athletes, so further studies are needed in this area. The results showed that there is a significant relationship between self-compassion and mental well-being in women athletes. In this context, a review study performed by Ferguson, Kowalski, Mack, \& Sabiston (2014) found that people experience negative emotions, such as sadness, sorrow, boredom, and failure in their lives. In order to deal with such negative emotions, they need to be relieved. Most importantly, they need to overcome such negative emotions without any harm. These people need to increase their self-compassion for these types of negative emotions. Researchers have reported that self-compassion increases mental well-being by increasing one's safety and calmness, one's inner connection with oneself, and reducing the threats and isolation that occur in individuals (Ferguson et al., 2014). Therefore, increasing selfcompassion causes greater emotional balance and increases the quality of life. Thus, when selfcompassion rises, psychological well-being is inherently increased, and although in some variables such as isolation and extremism, it can negate this relationship (Ferguson et al., 2014). Women athletes have higher self-compassion compared with non-athlete women, and this can increase their well-being than normal people. On the other hand, there was no association between self-compassion and public health. Studies have reported that self-compassion is an influential factor for emotional balance. It causes a feeling of self-care, awareness, an uncritical attitude towards one's inadequacies and failures, and therefore can affect public health because self-compassion requires the person to express his/her feelings. This process breaks the cycle of self-absorption, and the feeling of self-control and loneliness is decreased, and at the same time, the feeling of connection and connection is increased (Nicholls, Polman, \& Levy, 2012). Studies have shown that athletes have better general health than non-athletes. This factor can be one of the reasons for the lack of statistical significance. In another part, it is clear that selfcompassion has no mediating role in paths of 
perceived stress and psychological well-being. This indicates that this factor does not buffer the perception of stress in athletes and may affect the psychological well-being of female athletes. Brain mechanisms have shown that all people, including athletes who are members of the community, negatively react when exposed to stress, and this factor reduces mental well-being in these people, although experiences of stress exposure can affect the level of stress perception (Mosewich, Kowalski, Sabiston, Sedgwick, \& Tracy, 2011). Self-compassion was able to play a mediating role in the path of body image and mental well-being in female athletes, showing that athletes with higher self-compassion have a better body image and can better care about their body image, which ultimately increases their well-being and overall life satisfaction (Mosewich et al., 2011). Also, selfesteem associated with body image can potentially affect body image acceptance, which can enhance well-being (Wasylkiw, MacKinnon, \& MacLellan, 2012). It was also found that self-compassion did not have a mediating and effective role in the path of perceived stress and public health. This shows that perceived stress has a negative effect on public health, and self-compassion cannot influence this factor. Studies have demonstrated that stress perception should be decreased directly, and direct interventions on the reduction of stress would be able to ensure better health (Bauld \& Brown, 2009). Eventually, it became clear that selfcompassion alone could not mediate body image and general health. It is likely that the health of female athletes and their body image is adequately stimulated by exercise and physical activity, while self-compassion is not capable of mediating an axial role in this regard (Simms, Arnold, Turner, \& Hays, 2021). This study had some limitations, as it was performed during the COVID-19 pandemic, and the results may have been influenced by the negative consequences of the disease (Al Omari et al., 2020). In this study, only one questionnaire form was used, and it may not provide in-depth information about athletes. In this study, only women participated, and the interpretation of the results in men should be interpreted with caution. We also used athletes, and the results in the nonathlete population should be interpreted with caution. This study was conducted in Tehran and may not include other populations of Iran with other cultural characteristics. Also, the ages of individuals were in the category of youth and adults, and the interpretation of the results may change at other ages.

\section{Acknowledgments}

We wholeheartedly thank all women who participated in this research.

\section{Conflict of interest}

The authors declare no conflict of interest.

\section{References}

1. Adams, C. E., \& Leary, M. R. (2007). Promoting self-compassionate attitudes toward eating among restrictive and guilty eaters. Journal of social and clinical psychology, 26(10), 1120-1144.

2. Al Omari, O., Al Sabei, S., Al Rawajfah, O., Abu Sharour, L., Aljohani, K., Alomari, K., . . . Al Zubidi, B. (2020). Prevalence and predictors of depression, anxiety, and stress among youth at the time of CoViD-19: an online cross-sectional multicountry study. Depression research and treatment, 2020. 
3. Ansari, H., Bahrami, L., Akbarzade, L., \& Bakhasanim, M. (2007). Assessment of General Health and Some Related Factors among Students of Zahedan University of Medical Sciences In 2007. Zahedan J Res Med Sci, 9(4), e94755.

4. Association, W. M. (2013). World Medical Association Declaration of Helsinki: ethical principles for medical research involving human subjects. Jama, 310(20), 2191-2194.

5. Azizi A, Mohammadkhani P, Foroughi A A, Lotfi S, Bahramkhani M (2013). Psychometric Properties of Self-Compassion Scale(SCS). Practice in clinical psychology. 4(13), 47-59.

6. Badenes-Ribera, L., Fabris, M. A., \& Longobardi, C. (2018). The relationship between internalized homonegativity and body image concerns in sexual minority men: A meta-analysis. Psychology \& Sexuality, 9(3), 251-268.

7. barghi Irani, Z., bakhti, M., \& bagiyan agiyankulemare, M. J. (2015). The Effectiveness of a Cognitive Processing-based Social Skills Training on the Effectiveness of Cognitive Processing Based Training of Social Skills on, Emotional, Psychological Well-being and Reducing the Symptoms of Children with Conduct Disorder. Social Cognition, 4(1), 157-175.

8. Bauld, R., \& Brown, R. F. (2009). Stress, psychological distress, psychosocial factors, menopause symptoms and physical health in women. Maturitas, 62(2), 160-165.

9. Braun, T. D., Park, C. L., \& Gorin, A. (2016). Selfcompassion, body image, and disordered eating: A review of the literature. Body image, 17, 117-131.

10. Brown, T. A., Cash, T. F., \& Mikulka, P. J. (1990). Attitudinal body-image assessment: Factor analysis of the Body-Self Relations Questionnaire. Journal of personality assessment, 55(1-2), 135-144.

11. Cash, T. F. (2004). Body image: Past, present, and future: Elsevier.

12. Cohen, S., Kamarck, T., \& Mermelstein, R. (1994). Perceived stress scale. Measuring stress: A guide for health and social scientists, 10, 1-2.

13. Cooper, C. (2013). From stress to wellbeing volume 1: the theory and research on occupational stress and wellbeing: Springer.

14. Dahlenburg, S. C., Gleaves, D. H., Hutchinson, A. D., \& Coro, D. G. (2020). Body image disturbance and sexual orientation: An updated systematic review and meta-analysis. Body image, 35, 126-141.

15. Dijkstra, P., \& Barelds, D. P. (2011). Examining a model of dispositional mindfulness, body comparison, and body satisfaction. Body image, $8(4), 419-422$.

16. DuPont, C. M., Weis, T. M., Manuck, S. B., Marsland, A. L., Matthews, K. A., \& Gianaros, P. J. (2020). Does well-being associate with stress physiology? A systematic review and meta-analysis. Health Psychology, 39(10), 879.

17. Ebstrup, J. F., Eplov, L. F., Pisinger, C., \& Jørgensen, T. (2011). Association between the Five Factor personality traits and perceived stress: is the effect mediated by general self-efficacy? Anxiety, Stress \& Coping, 24(4), 407-419.

18. Ferguson, L. J., Kowalski, K. C., Mack, D. E., \& Sabiston, C. M. (2014). Exploring self-compassion and eudaimonic well-being in young women athletes. Journal of sport and exercise psychology, 36(2), 203-216.

19. Fornell, C., \& Larcker, D. F. (1981). Structural equation models with unobservable variables and measurement error: Algebra and statistics: Sage Publications Sage CA: Los Angeles, CA.

20. Friedman, H. S., \& Kern, M. L. (2014). Personality, Well-Being, and Health. Annual Review of Psychology, 65(1), 719-742. doi:10.1146/annurevpsych-010213-115123

21. Garfin, D. R., Thompson, R. R., \& Holman, E. A. (2018). Acute stress and subsequent health outcomes: A systematic review. Journal of Psychosomatic Research, 112, 107-113.

22. Gnam, J.-P., Loeffler, S.-N., Haertel, S., Engel, F., Hey, S., Boes, K., . . . Strahler, J. (2019). On the relationship between physical activity, physical fitness, and stress reactivity to a real-life mental stressor. International Journal of Stress Management, 26(4), 344.

23. Goldberg, D. P., \& Hillier, V. F. (1979). A scaled version of the General Health Questionnaire. Psychological medicine, 9(1), 139-145.

24. Gow, M. L., Tee, M. S., Garnett, S. P., Baur, L. A., Aldwell, K., Thomas, S., . . . Jebeile, H. (2020). Pediatric obesity treatment, self-esteem, and body image: A systematic review with meta-analysis. Pediatric obesity, 15(3), e12600.

25. Griffin, M. A., \& Clarke, S. (2011). Stress and wellbeing at work. APA handbook of industrial and organizational psychology, Vol 3: Maintaining, expanding, and contracting the organization., 359397.

26. Hair Jr, J. F., Hult, G. T. M., Ringle, C., \& Sarstedt, M. (2016). A primer on partial least squares structural equation modeling (PLS-SEM): Sage publications.

27. Hampel, P., \& Petermann, F. (2006). Perceived stress, coping, and adjustment in adolescents. Journal of Adolescent Health, 38(4), 409-415.

28. Henseler, J., Ringle, C. M., \& Sarstedt, M. (2015). A new criterion for assessing discriminant validity in variance-based structural equation modeling. Journal of the academy of marketing science, 43(1), 115-135.

29. Homan, K. J., \& Sirois, F. M. (2017). Selfcompassion and physical health: Exploring the roles of perceived stress and health-promoting behaviors. Health Psychology Open, 4(2), 2055102917729542.

30. Kantanista, A., Osiński, W., Borowiec, J., Tomczak, M., \& Król-Zielińska, M. (2015). Body image, BMI, and physical activity in girls and boys aged 14-16 years. Body image, 15, 40-43.

31. Kaveh, M., Alizadeh, H., Delavar, A., \& Borjali, A. (2011). Development of a Resilience Fostering Program against Stress and Its Impact on Quality of Life Components in Parents of Children with Mild 
Intellectual Disability. Journal of Exceptional Children, 11(2), 119-140.

32. Keyes, C. L., \& Magyar-Moe, J. L. (2003). The measurement and utility of adult subjective wellbeing.

33. Kline, R. B. (2011). Convergence of structural equation modeling and multilevel modeling: na.

34. Lai, R., \& Plakiotis, C. (2020). Stress and wellbeing of psychiatry trainees: a literature review. GeNeDis 2018, 117-126.

35. Lemes, D. C. M., Câmara, S. G., Alves, G. G., \& Aerts, D. (2018). Body image satisfaction and subjective wellbeing among ninth-grade students attending state schools in Canoas, Brazil. Ciencia \& saude coletiva, 23, 4289-4298.

36. Maroufizadeh, S., Zareiyan, A., \& Sigari, N. (2014). Reliability and validity of Persian version of perceived stress scale (PSS-10) in adults with asthma. Archives of Iranian medicine, 17(5), 0-0.

37. Morrison, M. A., Morrison, T. G., \& Sager, C.-L. (2004). Does body satisfaction differ between gay men and lesbian women and heterosexual men and women?: A meta-analytic review. Body image, 1(2), 127-138.

38. Mosewich, A. D., Kowalski, K. C., Sabiston, C. M., Sedgwick, W. A., \& Tracy, J. L. (2011). Selfcompassion: A potential resource for young women athletes. Journal of sport and exercise psychology, 33(1), 103-123.

39. Namazi, A., Alizadeh, S., \& Kouchakzadeh-Talami, S. (2015). The correlation between general health, emotional intelligence and academic achievement together on midwifery students. Journal of Clinical Nursing and Midwifery, 4(2), 20-28.

40. Neff, K. (2003). Self-compassion: An alternative conceptualization of a healthy attitude toward oneself. Self and identity, 2(2), 85-101.

41. Neff, K., \& Sands, X. (2015). Self-compassion: The proven power of being kind to yourself: William Morrow New York, NY.

42. Neff, K. D. (2003). The development and validation of a scale to measure self-compassion. Self and identity, 2(3), 223-250.

43. Neff, K. D. (2011). Self-compassion, self-esteem, and well-being. Social and personality psychology compass, 5(1), 1-12.

44. Neff, K. D. (2016). The self-compassion scale is a valid and theoretically coherent measure of selfcompassion. Mindfulness, 7(1), 264-274.

45. Nicholls, A. R., Polman, R. C., \& Levy, A. R. (2012). A path analysis of stress appraisals, emotions, coping, and performance satisfaction among athletes. Psychology of sport and exercise, 13(3), 263-270.

46. Otter, R., Brink, M. S., van der Does, H., \& Lemmink, K. (2016). Monitoring perceived stress and recovery in relation to cycling performance in female athletes. Int J Sports Med, 37(1), 12-18.

47. Perez-Blasco, J., Sales, A., Meléndez, J. C., \& Mayordomo, T. (2016). The effects of mindfulness and self-compassion on improving the capacity to adapt to stress situations in elderly people living in the community. Clinical Gerontologist, 39(2), 90103.

48. Pop, C. L. (2017). Physical activity, body image, and subjective well-being. Well-being and quality of life. Medical Perspective, Edition, 1-19.

49. Raab, K. (2014). Mindfulness, self-compassion, and empathy among health care professionals: a review of the literature. Journal of health care chaplaincy, 20(3), 95-108.

50. Seligman, M. E., Rashid, T., \& Parks, A. C. (2006). Positive psychotherapy. American psychologist, 61(8), 774.

51. Shakori, S., Khosrojavid, M., \& Salehi, I. (2015). Comparison of Self-Regulation, Personality Traits and Family Functions in Gifted Students, Average Intelligence Students and Students in Technical Schools. Quarterly Journal of Child Mental Health, 2(2), 59-71.

52. Sheivandi, K., Naeimi, E., \& Farshad, M. r. (2016). The structural model of self-compassion and psychological well-being, self-esteem and body image among female students of Shiraz University with mediator. Clinical Psychology Studies, 6(24), 115-133. doi:10.22054/jcps.2016.6526

53. Simms, M., Arnold, R., Turner, J. E., \& Hays, K. (2021). A repeated-measures examination of organizational stressors, perceived psychological and physical health, and perceived performance in semi-elite athletes. Journal of sports sciences, 39(1), 64-77.

54. Steptoe, A., Deaton, A., \& Stone, A. A. (2015). Subjective wellbeing, health, and ageing. The Lancet, 385(9968), 640-648. doi:https://doi.org/10.1016/S0140-6736(13)61489$\underline{0}$

55. Tabachnick, B. G., Fidell, L. S., \& Ullman, J. B. (2007). Using multivariate statistics (Vol. 5): Pearson Boston, MA.

56. Tabatabaei, S., \& Rasouli, Z. (2018). The Reliability and validity of Persian Version of the General Health Questionnaire (GHQ-60) in Industry Staff. Iran Occupational Health Journal, 15(3), 45-54.

57. Tiggemann, M. (2012). Sociocultural perspectives on body image Encyclopedia of body image and human appearance, Vol. 2 (pp. 758-765). San Diego, CA, US: Elsevier Academic Press.

58. Tissera, H., Auger, E., Séguin, L., Kramer, M. S., \& Lydon, J. E. (2020). Happy prenatal relationships, healthy postpartum mothers: a prospective study of relationship satisfaction, postpartum stress, and health. Psychology \& Health, 1-17.

59. Vartanian, L. R. (2012). Self-discrepancy theory and body image. Encyclopedia of body image and human appearance, 2(1), 711-717.

60. Walker, D. C., White, E. K., \& Srinivasan, V. J. (2018). A meta-analysis of the relationships between body checking, body image avoidance, body image dissatisfaction, mood, and disordered eating. International Journal of Eating Disorders, 51(8), 745-770.

61. Wasylkiw, L., MacKinnon, A. L., \& MacLellan, A. M. (2012). Exploring the link between self- 
compassion and body image in university women. Body image, 9(2), 236-245.

62. Wollast, R., Riemer, A. R., Bernard, P., Leys, C., Kotsou, I., \& Klein, O. (2019). How selfcompassion moderates the effect of body surveillance on subjective happiness and depression among women. Scandinavian Journal of Psychology, 60(5), 464-472. doi:https://doi.org/10.1111/sjop.12553

63. Wood-Barcalow, N. L., Tylka, T. L., \& AugustusHorvath, C. L. (2010). "But I like my body": Positive body image characteristics and a holistic model for young-adult women. Body image, 7(2), 106-116.

64. Zarshenas, S., Karbalaaei Noori, A., Hosseini, S. A., Rahgozar, M., Seyednour, R., \& Moshtagh, N. (2010). The effects of aerobic exercise on body image attitudes in women. Journal of Rehabilitation, 11(2), 15-20.

65. Zessin, U., Dickhäuser, O., \& Garbade, S. (2015). The Relationship Between Self-Compassion and Well-Being: A Meta-Analysis. Applied Psychology: Health and Well-Being, 7(3), 340-364. doi:https://doi.org/10.1111/aphw.12051. 